\section{Council's criticisms start row}

\section{Tokyo}

JAPAN's special Council on Education, set up to prepare a blueprint for a massive reform of the education system, delivered its first set of recommendations last week to a chorus of complaints and disapproval.

It is only ten months since the council, with its 25 members all personally picked by Prime Minister Yasuhiro Nakasone, began its activities, so it is perhaps not surprising that it has been unable to reconcile all the fiercely held views on this emotive subject. But the report is more of a philosophical declaration than a practical recipe for reform.

The report castigates the present education system in terms which, if they had been written by a foreigner, would probably have given rise to complaints of anti-Japanese prejudice. The system is accused of producing "too many stereotyped persons without strong individuality" who are not "able to think and judge on their own" because they have been taught only to "memorize information and facts". "Bullying in school, pupils' absenteeism, violence at school and juvenile delinquency" are also described as "grave" and as products of the present system, although Japanese schools are havens of peace compared with those in the West.

To remedy this situation, strong emphasis is placed on the fostering of "individuality". But although this Western notion is repeatedly endorsed, far more column inches of the report are given over to the need to reinforce distinctively Japanese values: children "must love Japan", maintain "a deep understanding and love of Japanese culture" and have "identity as Japanese". These values were, of course, inculcated in the education system that existed before the Second World War, Wuich, indeed, comes in for some oblique praise, while post-war education is criticized for putting "a disproportionate emphasis on rights instead of duties". To the Socialist and Communist parties (the second and fourth largest parties in the Diet) such statements are like a red rag to a bull and they have attacked the report furiously, pointing out the difficulties in a system which is meant to teach people to "think independently" while "fostering Japanese who will inherit the traditional culture".

Philosophical contradictions aside, the report is firm in identifying the real villain behind educational woes: a society that gives too much preference to graduates from leading universities. Because top corporations and ministries recruit from just a few universities, the whole educational system has become oriented towards success in the university entrance examination "hell". In that examination, all that counts is overall score in multiple choice questions; the higher one's score

\section{Soviet Antarctica}

the better the university (or faculty) one can enter, regardless of vocation and aptitude. The report makes an appeal for a change in attitudes away from a society oriented towards "academic record", but clearly such changes are beyond its power to effect.

A more direct attack is made on the university entrance examination. A new first-stage unitary examination is proposed for use by all universities, public and private, to replace that now used only by public universities. The burden on students, who usually try more than one kind of examination, would thus be eased.

To try to ease competition further down the system, new kinds of schools are proposed that will fuse junior and senior

high-school. Entrance examinations for high-schools have recently become almost as fraught as the university entrance examinations themselves. It is suggested that some such schools work on a credit system for high-school graduation rather than rely on intensive examinations to increase the flexibility of the system.

The Council on Education will now soldier on for a further two years, trying to build on this somewhat shaky start. The Prime Minister is giving full backing to the council, and a cabinet-level group is expected to be formed to put its weight behind its recommendations. So far, however, teachers are opposed, the Japan Teachers Union having sworn to fight the reforms "to the end" a few days before the report was even published. The teachers' main concern is to get average class sizes down to 35 from present levels which are closer to 40 pupils.

Alun Anderson

\title{
Trapped vessel in good shape
}

THE Soviet research vessel Mikhail Somov, which has been trapped in the Antarctic pack-ice for more than three months, could eventually drift to safety along a route mapped by a previous expedition aboard the same vessel. Accord-

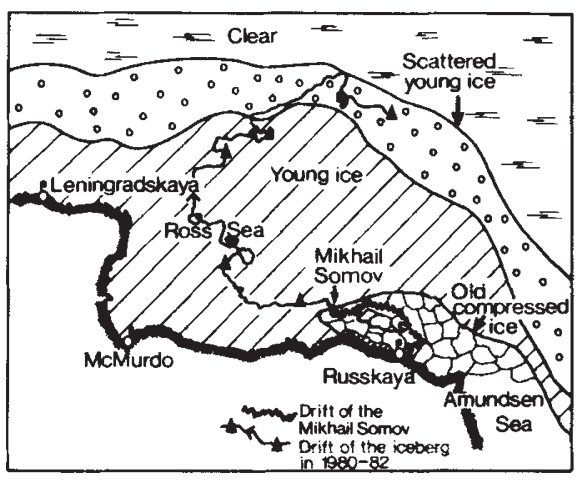

ing to Candidate of Sciences Al'bert A.

Romanov, of the Arctic and Antarctic Research in Leningrad, the ship's present course virtually coincides with that of an iceberg, mapped by radio beacon as part of a Franco-Soviet experiment in 198082. The tagged berg drifted on a semicircular course for more than 3,400 nautical miles before emerging into the warm waters of the Pacific.

The planners of the 30th Soviet Antarctic expedition, of which Mikhail Somov is the flagship, do not, however, intend to leave the crew and research personnel trapped for so long. Some 77 people have already been flown out by helicopter, leaving 53 on board for essential ship maintenance and observations of conditions in this previously unexplored sector of the Antarctic. (Conditions are severe, with winds of 17 metres per second, temperatures of $-25^{\circ} \mathrm{C}$, poor visibility, snowstorms and fog.) Meanwhile, a special taskforce has been established under the deputy head of the state committee for hydrometeorology and environmental control to "ensure a rapid solution" of the "Somov problem". The icebreaker Vladivostok of the Far Eastern Shipping Line has been sent south, and is expected to approach Mikhail Somov at the beginning of July.

Because Mikhail Somov, with its now reduced complement, is well provisioned for another 10 months, evacuation plans are, so far, of a contingency nature only. A specially adapted Mi-8 helicopter is on board the Vladivostok to evacuate the Somov personnel in case of emergency.

For the moment, Vladivostok's chief role will be to try to break a channel through to the trapped vessel and, if necessary, tow it out. If Somov could break through into the relatively young ice of the Ross Sea, the most difficult part of the mission would be over. Meanwhile, scientists are continuing their work aboard the trapped vessel, including, presumably, the seismo-acoustic probing of the sea-bed that was a major feature of the ship's original programme. It is unfortunate that Soviet plans to have all seven permanent Antarctic stations equipped with Inmarsat receiving and transmitting equipment have not yet been implemented. So far only one such station, the Molodezhnaya observatory in Enderby Land, is so equipped, while the two nearest to the trapped ship, Russkaya and Leningradskaya, are linked to Leningrad only by shortwave radio.

Vera Rich

\section{Correction}

There was an error in last week's story about laser fusion (Nature 27 June, p.706): the current budget for inertial confinement fusion is about $\$ 140$ million; the administration proposed halving this sum in the fiscal year 1986. 